\title{
La Tolerancia entre Culturas como Procedimiento para la Paz
}

\author{
JUAN ESCÁMEZ SÁNCHEZ \\ Universidad de Valencia
}

\begin{abstract}
SUMMARY.-This article analyze the function of the attitude of the tolerance, to the understanding and the peace, among people belonging to the different cultures. The explanation can be articulated into the following sections: people are different according to the diverses cultures; the right to difference; the cultural identity generates conflicts; the tolerance as a predisposition to the understanding; the education process in the tolerance.
\end{abstract}

\section{LA PAZ, UNA UTOPÍA EN PELIGRO}

Se han cumplido cinco años que, con la caída del muro de Berlín y la finalización de la guerra fría entre el este y el oeste europeo, parecía que entrábamos en una nueva época en la que era posible vivir aquel valor existencia ${ }^{1}$ que, desde los tiempos más antiguos hasta los nuestros, es compartido transculturalmente por muchos pueblos: «vivir en un mundo en paz». Sin embargo, nuestro sueño ha sido roto por los graves conflictos actuales entre etnias, culturas, religiones, intereses económicos que han surgido en los diferentes países de la antigua Unión de Repúblicas Socialistas Soviéticas, en las nuevas repúblicas desmembradas de la ex Yugoslavia, en el Golfo Pérsico, en Ruanda; con unas secuelas de destrucción, muerte y hambre que horrorizan a la racionalidad y al sentimiento de los humanos.

Estos brutales acontecimientos han ampliado tanto el umbral de nuestra sensibilidad que la situación de los kurdos en Turquía, de los turcos en Alemania, de los magrebíes en Francia, de los latinoamericanos y africanos en España, de las minorías indígenas en la América desde Alaska al Cabo de Hornos, apenas nos generan desasosiego. A pesar de nuestra tranquilidad, el hambre, la marginación y el desprecio a culturas y grupos minoritarios constituyen una vulneración de los derechos humanos fundamentales, así como una transgresión a la justicia que nos dicta lo que deberíamos hacer con nuestros semejantes.

Ante tales realidades, me he preguntado qué papel juega el ideal de la paz y he recordado aquella sentencia de $\mathbf{M}$. Weber: «... lo posible ha sido alcanzado frecuentemente sólo porque se ha intentado algo imposible que está más allá de nuestro poder». Las ilusiones conscientes y útiles son un buen acicate, una excelente ayuda para hacer lo 
que, en realidad, está en nuestras manos hacer. Los ideales, por lo tanto, no son una excrecencia a eliminar de nuestro horizonte sino una auténtica necesidad para vivir como personas y para que, en concreto, el orden moral obtenga un adecuado cumplimiento $^{2}$. Para conseguir que la paz sea una realidad tenemos que actuar como si fuera posible. Podemos concebir el ideal de «un mundo en paz» como algo que aunque es muy difícil (casi imposible) que se realice, los pequeños esfuerzos que hagamos para su puesta en marcha cambiarán la existencia humana.

Desde esta convicción, y sólo desde ella, me parece justificado exponer algunas reflexiones sobre el papel de la tolerancia en la construcción de la paz; y hacerlo desde un planteamiento de matiz pedagógico, ya que ese es el oficio que desempeño. Articularé mi exposición en los siguientes apartados: a) las personas son diferentes según las diversas culturas; b) el derecho a la diferencia; c) las identidades culturales generan conflictos; d) la tolerancia como predisposición para la comprensión; y e) el proceso de educación en la tolerancia.

\section{LAS PERSONAS SON DIFERENTES SEGÚN LAS DIVERSAS CULTURAS}

Desde M. Scheler ${ }^{3}$, ha surgido una imagen contemporánea del hombre, en las diversas antropologías, como la de un «ser abierto al mundo» frente al enclaustramiento del animal en un medio. Esta imagen es debida a las diversas investigaciones que han demostrado la inmadurez y no especialización de las estructuras biológicas del humano. El hombre está orgánicamente desvalido, sin armas naturales, sin órganos de ataque, defensa o huida, con sentidos de una eficacia no muy significativa. Los órganos especializados de los animales superan con creces cada uno de nuestros sentidos ${ }^{4}$. La inmadurez e inespecialización del ser humano lo muestran como un ser no fijado, no acabado por la naturaleza. De ello se siguen dos características; por una parte, que el humano es un ser naturalmente «indigente», «de carencias», $y$, por otra, que tiene una enorme plasticidad para ser de una manera u otra.

Debido a sus carencias biológicas, es decir, debido a que su naturaleza no le asegura las respuestas que necesita para dar cumplida satisfacción a las necesidades de su vivir, el humano tiene que inventar tales respuestas; de ahí deriva la posibilidad de, por su acción, construir mundos culturales. La acción del humano tiene una significación radical; ejecutar actos resolutorios de los problemas de su vivir. Y el conjunto de esos actos, en el devenir histórico de un pueblo, constituye su cultura. El hombre vive como ser cultural, es decir, de los productos de su acción previsora, planificada y mancomunada que le permite procurarse instrumentos y técnicas para resolver su vida, transformando los conjuntos muy diversos de las condiciones naturales de su medio.

La plasticidad del hombre y su vivir como ser cultural quiere decir que cada persona concreta está configurando, construyendo su propia personalidad a partir de su cultura,

2. Sádaba, J. (1991), «Normas e ideales». En Muguerza, J.; Quesada, F. y Rodríguez, R. (Eds.), Etica día tras día. Madrid, Trotta, pp. 369-376.

3. Scheler, M. (1938), El puesto del hombre en el cosmos. Buenos Aires, Losada.

4. Gehlen, A. (1993), Antropología filosófica. Barcelona, Paidós, pp. 63-67. Cfr. Gehlen, A. (1980), Una imagen del hombre. Salamanca, Sígueme. 
de los productos de las acciones de sus antepasados y de las acciones propias. Como tales acciones se suceden como respuestas a unas necesidades vitales concretas en unas situaciones determinadas, tenemos que los productos $\mathrm{u}$ objetos culturales son diversos, que las culturas son distintas y que las personas son realmente diferentes, según cada una de las culturas a la que pertenezcan. La antropología cultural confirma de modo claro esta hipótesis. Cada una de las numerosas culturas primitivas representa un mundo típico, inconfundible. La fluidez de la vida pulsional del humano, la vivacidad de su capacidad de imaginar proyectos, la variedad de circunstancias externas, frente a las que reacciona cada vez, han producido una exuberante variedad de mundos culturales.

La vida y la cultura están entreveradas en el ser humano como dos elementos complementarios; cada uno de ellos dice relación necesaria al otro. La estructura biológica humana exige la cultura, y la cultura es el medio ambiente que posibilita el vivir humano. Podríamos decir más, la vida del ser humano es cultura y el modo concreto de nuestro vivir, del vivir de cada uno, depende de la peculiar cultura en la que hemos nacido y donde se desarrolla ese fluir constante de sucesos al que llamamos nuestra propia vida; somos, en cierto modo, nuestra cultura que adquiere así carácter constitutivo de nuestra realidad subjetiva.

La indigencia y plasticidad del humano se nos muestra, de un modo eminente, en el niño recién nacido; es un ser con enormes carencias, ante las cuales las demás personas le prestan ayuda; son los demás quienes, con su solicitud y cuidados, se incrustan en la vida del niño, y esa incrustación es tal que configura, moldea, conforma su primera personalidad $^{5}$. Los demás le proporcionan un lugar dónde habitar, utensilios de comer y vestir, estímulos y silencios, sonrisas y gestos, en definitiva, todo un ambiente que rodea al niño desde el principio y sin el cual no podría vivir o, por lo menos, no podría llevar lo que entendemos por «vida humana». El niño, desde sus primeros momentos, se encuentra entreverado con los demás que se introducen en su vida otorgándole unos modos humanos: gestos, lenguaje, usos, costumbres, instrumentos.

Aún más, el niño queda vinculado a la mentalidad de la cultura a la que pertenece. La mentalidad la constituyen los modos cómo se enseña a pensar, a sentir, a conducirse en la vida. La mentalidad configura a la concreta personalidad del niño dotándola de prácticas sociales, de significados y valores, de maneras de pensar y sentir, de modos de ser y actuar que no son naturales, que no son «silvestres», sino que exclusivamente surgen en el seno de una cultura ${ }^{6}$. El idioma, las costumbres, el derecho, la religión, el arte, la economía son los ingredientes que confieren a la vida biológica, puramente natural, su forma biográfica, su condición concretamente humana.

Una cultura, como realidad objetiva con significación propia, es el horizonte vital de los humanos que pertenecen a ella; sus comportamientos no pueden entenderse sin el sistema de significados que constituyen tal cultura; en términos más precisos, los pensamientos, los deseos, los motivos y los proyectos de cada persona son generados a partir del sistema de significados de la específica cultura que los hace posibles ${ }^{7}$. Los significados culturales guían y condicionan las acciones individuales.

5. Zubiri, X. (1986), Sobre el hombre. Madrid, Alianza Editorial, pp. 223-341.

6. Pinillos, J. L. (1989), «El problema de las mentalidades», en Rodríguez, A.; Seoane, J., Creencias, actitudes y valores. Madrid, Alhambra, pp. 451-468.

7. Bruner, J. S. (1991), Actos de significado. Más allá de la revolución científica. Madrid, Alianza Editorial, pp. 47-55. 
Así, una determinada cultura produce una manera «natural» de ver las cosas. Los modos de conducta, las maneras de pensar, las formas de sentir y reaccionar generadas en una determinada cultura les parecen «naturales» a quienes han crecido en ella; en cambio, a los que no son miembros de esa cultura, con mucha frecuencia, les parecen risibles, inauditos o reprochables. Lo que sucede, ordinariamente, es que las interpretaciones que las personas hacemos de la realidad, desde nuestro contexto cultural, las vivimos con pretensión de verdad absoluta y, por ello, difícilmente son compatibles con otras interpretaciones efectuadas, por otras personas, desde contextos culturales diferentes. La persona socializada en una cultura tiende a acentuar sus semejanzas con aquellas personas que pertenecen a su cultura, a la misma vez que a intensificar sus diferencias con las personas de otras culturas, y esto no sólo a nivel cognitivo sino también afectivo y comportamental; con ello aparecen los estereotipos, la discriminación, los conflictos que, con frecuencia, degeneran en situaciones violentas.

\section{EL DERECHO A LAS DIFERENCIAS}

Como he venido afirmando, cada persona ha construido su real personalidad en el seno de una cultura concreta; ha incorporado a su naturaleza un repertorio de patrones simbólico-culturales, a modo de código esencial extragenético, susceptible de guiar y dar sentido a su vida; ha construido su identidad como sujeto ${ }^{8}$. Y esto significa que lo que cada persona es, piensa, siente y hace, se debe, en una parte muy significativa, a su cultura. Si estamos de acuerdo en que esto es así, se produce el problema de la incomunicación entre personas de diferentes culturas. ¿No sería conveniente, en un momento en el que el mundialismo es una tendencia generalizada, propugnar una cultura única en la que el entendimiento entre los humanos sea posible? ¿Qué cultura sería esa?

Aunque el problema de la incomunicación y sus consecuencias es un hecho, al que después haremos referencia, expondré algunas razones para justificar el derecho, y aún la conveniencia, a la diferencia. La primera de ellas, y a mi juicio la más radical, está en la dignidad humana; tal dignidad se convierte en un concepto vacío si no está referida a la dignidad de cada una de las personas en la concreta realidad que ha llegado a ser. La dignidad de las personas reales y concretas exige, recordando a Kant, ser consideradas como fin en sí mismas y no como medios para nada ni para nadie. La dignidad de cada persona exige ser respetada en su personal identidad. Erradicarlas de su cultura conduciría a hacerlas extrañas a sí mismas, alienarlas.

El derecho a la diferencia se fundamenta también en otra de las características de las personas que ha dado lugar a muchos de los derechos humanos; me estoy refiriendo a la libertad entendida como auto-determinación. Cada pueblo y cada persona tienen que ser reconocidos como libres para establecer y perseguir aquellos fines que han considerado o consideran como dignos de ser preferidos. Se trata de recabar, como ha señalado Savater $^{9}$, la soberanía efectiva de cada pueblo y de cada uno sobre sí mismo. Cada cultura

8. Jordan, J. A.; Etxeberría, F. (1994), «Identidad cultural y educación en una sociedad global». Ponencia presentada al XIII Seminario de Teoría de la Educación. Tarragona.

9. Savater, F. (1991), «La gestión de la pluralidad moral», en Muguerza, J.; Quesada, F. y Rodríguez, R. (eds.), Etica día tras día, obr. cit., p. 384. 
ha surgido como conjunto de respuesta a las necesidades, circunstancias y condiciones con las que unos humanos se han encontrado; y esas necesidades, circunstancias y condiciones no son universalizables, sino concretas e históricas, a las que se les ha ido encontrando respuestas, más o menos satisfactorias, para ir viviendo y, con frecuencia, ir siendo aceptablemente felices; y esos hallazgos sobre los modos de ser felices parece que han de ser respetados y no substituidos por lo que otros, $u$ otras culturas, impongan.

Como he expuesto en otra situación ${ }^{10}$, cada cultura tiene un valor en sí misma puesto que está constituida por un conjunto de creencias, valores, actitudes, usos y costumbres adaptados para que, de un modo único e irrepetible, un pueblo solucione sus necesidades; el conocimiento y comprensión de los otros, nos puede conducir a otras formas de ver, sentir y actuar que son complementarias de los modos de conocer, evaluar la realidad y orientar nuestras acciones en la relación que sostenemos con los demás y con la naturaleza; el etnocentrismo, al situar el mundo según un peculiar modo de concebirlo, por muy justificado y adecuado que sea para las personas de una cultura, no deja de ser un modo peculiar e interesante, pero que, sin lugar a dudas, pierde las perspectivas que aportan los individuos de las demás culturas.

No podemos tomar a la ligera que, en nuestro planeta, hay identificadas alrededor de 3.500 lenguas habladas, de las que alrededor de 500 tienen expresión escrita y, de ellas hay 16 lenguas que son habladas por más de 50 millones de personas ${ }^{11}$, siendo, cada una de esas lenguas, la encarnación de largas tradiciones y una expresión de la pluralidad y diversidad culturales del mundo. Parece correcto pensar que cada cultura existente desvela sectores de valores humanos, llamados a fecundar a cualquier otra cultura que se muestre abierta al mutuo reconocimiento; cada cultura particular puede entenderse como un arco en el círculo total de la satisfacción de las necesidades y aspiraciones de los humanos, aportando a ese tesoro común, que llamamos humanidad, una parte original e insustituible.

El derecho a la diferencia es difícil de aceptar porque pone en cuestión aquel postulado de la Ilustración sobre la existencia de una racionalidad ideal que nos garantiza un modo seguro de conocer la naturaleza y de proceder en nuestras relaciones con los demás, y ello porque, de modo ilegítimo, no se tenía presente, por los ilustrados, el carácter ligado al contexto histórico y social que necesariamente tiene cualquier conjunto sustantivo de principios de racionalidad, sean teóricos, referidos a la verdad, o prácticos, referidos a la moralidad. Como nos ha dicho MacIntyre ${ }^{12}$, tanto los pensadores de la ilustración, como sus sucesores, se mostraron incapaces de ponerse de acuerdo acerca de cuáles eran precisamente aquellos principios que serían innegables para todas las personas racionales. Un tipo de respuesta fue dada por los autores de la Enciclopedia, un segundo por Rousseau, un tercero por Bentham, un cuarto por Kant. Por consiguiente, el legado de la ilustración ha sido proporcionar un ideal de justificación racional que ella misma ha demostrado imposible de alcanzar.

10. Escámez, J. (1992), «Comunicación personal en contextos interculturales». Revista P'ADE, vol. II, $\mathbf{n}^{\mathrm{o}} 1$, pp. 35-49.

11. Macbride, S. y cols. (1980), Comunicación e información en nuestro tiempo. México, F. C. E., pp. 94-97.

12. MacIntyre, A. (1994), Justicia y Racionalidad. Barcelona, Ediciones Internacionales Universitarias, p. 23. 
Aplicando lo anterior al tema que nos ocupa, al derecho a la diferencia según tradiciones culturales, se nos manifiesta que no hay criterio racional alguno que pueda justificar la bondad de una cultura por encima de las demás; y ello porque toda justificación racional, sobre la verdad y la justicia, se hace desde una cultura particular. Cada cultura puede, en todo estadio de su desarrollo, proporcionar una justificación de sus características centrales, empleando los conceptos y los criterios por los que se define a sí misma; pero no hay algún conjunto de criterios independientes de justificación racional por apelación al cual podamos establecer que una cultura sea mejor que otra ${ }^{13}$.

No quisiera que mis anteriores declaraciones se interpretaron como una defensa del relativismo cultural, el que todas las culturas sean igualmente valiosas, ni siquiera como un perspectivismo intelectual. Lo primero sería una grave injusticia ya que los miembros de una cultura tienen un compromiso total con ella puesto que, como hemos dicho, son una encarnación de la misma; y esto no puede tomarse como un alegre divertimento. La lealtad a la propia cultura, a sí mismo, es un asunto serio que prohibe el que todo nos sea igual. El perspectivismo tampoco aporta mucho, ya que la multiplicidad de culturas no proporciona solamente una multiplicidad de puntos de vista, sino una multiplicidad de compromisos personales, a veces antagónicos, con la vida y con uno mismo.

A mi juicio, Victoria Camps ${ }^{14}$ apunta una correcta solución con su propuesta de atendernos a la pragmática real. Puesto que tenemos la «Declaración Universal de los Derechos Humanos», ahí tenemos un punto de referencia, un criterio. Las diferencias, tanto individuales como culturales, han de ser salvadas y defendidas de intromisiones y alienaciones, siempre y cuando, al mismo tiempo, se preserven y queden garantizados los contenidos básicos de la justicia, la dignidad y la humanidad. Respecto a estos no son aceptables los relativismos. Es preciso que los derechos humanos se hagan, de hecho, universales, si los reconocemos como tales derechos, y ello nos obliga a luchar por la transformación de las conciencias ajenas a ellos. Ahora bien, esos derechos nos obligan tanto a tolerar y respetar otras ideas, otras costumbres y otras libertades, como a castigar y reprimir las violaciones de los mismos derechos. La existencia de esos universales no requiere la homogeneización, ya que sólo cuando existe la discrepancia y la diferencia son interesantes la discusión y el diálogo.

\section{LA PERTENENCIA A CULTURAS DISTINTAS GENERA CONFLICTOS}

Los conflictos entre personas de diferentes culturas son un hecho y los hechos, como decía un amigo mío, son tozudos y están ahí. Quizás una de las aportaciones que podamos hacer sea explicarlos. ¿Por qué son tan frecuentes esos conflictos? ¿Cuáles son las razones? Creo que la primera de ellas es la falta de conocimiento sobre las reales diferencias; somos diferentes unos de otros porque cada uno somos nuestra cultura, y un poquito más. Si no partimos de la realidad de la diferencia, buscaremos homogeneizaciones artificiales y pretensiones ilusorias de comprensión de los demás. Somos diferentes

13. Ibid., pp. 333-349.

14. Camps, V. (1991), «El derecho a la diferencia», en Muguerza, J.; Quesada, F. y Rodríguez, R., Etica día tras día. Obr. cit., pp. 67-78. 
y tenemos derecho a serlo. Y aceptar esa plural diversidad nos pone en el camino de reconocernos en nuestra cultura como a los demás en la suya.

En segundo lugar, que la comunicación entre personas de distintas culturas es muy difícil; en otro momento y lugar dije que existe una desestructuración en la comunicación. Dos reflexiones nos pueden aclarar este asunto. En toda comunicación personal intentamos comunicar ciertas cosas a nuestro oyente. Se manifiesta nuestra intención de comunicar algo, un significado, buscando comprensión. Para que se dé una buena comunicación el significado tiene que ser compartido por el emisor y el receptor; y esto, en la comunicación entre personas de distintas culturas, se encuentra con obstáculos graves. En efecto, la percepción y categorización que, en cada cultura, se hace de la realidad es desde esquemas cognitivos distintos, por lo que respecto a un mismo evento, suceso u objeto social pueden darse, y se dan frecuentemente, interpretaciones muy diferenciadas $y$, a veces, divergentes o contradictorias. La diferencia de esquemas cognitivos, por razones de tipo cultural, origina disonancia semántica entre emisor y receptor, con lo que la comunicación es muy difícil.

Además, cada cultura presenta un núcleo de creencias y valores característicos que impregna la vida de los miembros de esa cultura. Le son tan «propios» que configuran su personal modo de vivir. Vivimos la vida humana en ellos y desde ellos. Nos son tan cotidianos como el aire que respiramos, el sol que nos calienta o la luz que nos ilumina. Desde ellos evaluamos y tomamos decisiones. Las creencias y los valores de una cultura no son imaginaciones sino realidades que impregnan la identidad de los pueblos y las personas. Quien cuestiona las formas de vida en las que ha construido su identidad propia, tiene que cuestionar también la propia existencia ${ }^{15}$. Los valores de una cultura son las convicciones que responden, desde el horizonte de las certidumbres del mundo vital, a aquellas cuestiones sobre lo que es verdadero, bueno y correcto hacer.

Si nuestros modos de conocer y nuestros modos de evaluar nos son tan «naturales», responden tan claramente a lo que es «verdadero»y «justo», reflejan tan exactamente el modo de ser de las cosas y de lo que deberían ser nuestras acciones, entonces esos modos de conocer y evaluar no pueden ser puestos en tela de juicio, sin ponernos en cuestión a nosotros mismos; de lo contrario, desaparecerían las certidumbres vitales sobre lo que somos, conocemos y hacemos; desaparecerían las certidumbres desde las que nos reconocemos.

Por ello tenemos que ser conscientes de la dificultad de entendimiento entre culturas y la proclividad a los conflictos. Lo que en una cultura es «verdadero», en otra no lo es tanto, lo que en una es estimado, hasta lo heroico, en otra es despreciado. Esta situación se está viendo agravada en nuestros días por motivaciones políticas que se manifiestan en la explosión violenta de conflictos étnicos y nacionalistas que parecían olvidados. Como nos ha recordado José $\mathrm{M}^{\mathrm{a}}$ Puig ${ }^{16}$, nadie desconoce que la convivencia étnica, religiosa y cultural se rompe continuamente en muchas partes del mundo, y está siendo destruida mediante guerras en algunos puntos de la misma Europa; otras veces la

15. Habermas, J. (1985), Conciencia moral y acción comunicativa. Barcelona, Península, pp. 207-209.

16. Puig, J. M. (1994), «Diversidad étnico-cultural: una prueba para la democracia y para la educación». En Santos Rego, M. (ed.), Teoría y práctica de la educación intercultural. BarcelonaSantiago de Compostela, P. P. U. Universidad de Santiago, pp. 97-118. 
convivencia es substituida por la violencia que engendran algunos grupos xenófobos y racistas.

No sólo en Europa sino en España, en bellas palabras de Antonio Gala ${ }^{17}$, culpar a otros de los males económicos o políticos que nos asaltan es un viejo desatino. Desde los Reyes Católicos se viene haciendo. Ellos amputaron, del tronco común, las grandes ramas árabes y judías. Y redujeron esta yacija, donde las tres culturas procrearon nuestros momentos más resplandecientes, a límites paupérrimos. La tolerancia se substituyó por la intransigencia; la diversidad, por la ortopedia; la mezcla germinativa por la esterilidad. De aquellos polvos vienen estos lodos: el encaramarse unos vecinos sobre los demás, la vanidad de imaginarios factores físicos distintivos, los nacionalismos insolidarios, el empequeñecimiento de los ideales, las encontradas políticas de campanario. La xenofobia, que es un error histórico, se encarna hoy en el error cotidiano del racismo, usado a menudo por gobernantes torpes o torpes ciudadanos como coartada para achacar a los otros nuestras escaseces, sinsabores y responsabilidades.

Sin embargo, y a pesar de las dificultades, la comprensión entre las culturas y entre los miembros de diversas culturas es posible, si se dan determinadas condiciones, porque las culturas no son realidades estáticas sino dinámicas, y los miembros de una cultura, a pesar de la configuración de la personalidad recibida de ella, son entre sí más diferentes y flexibles de lo que ciertos planteamientos etnográficos, de antropología cultural y de psicosociología pretenden demostrar. Es cierto que la persona está configurada por su cultura, pero la relación que mantiene con ella es dinámica ya que no sólo hereda tal cultura sino que la recrea ${ }^{18}$.

A lo largo del proceso de enculturación, el encuentro de la persona con su cultura se produce en la relación con personas que no la poseen en su totalidad, sino que han hecho su síntesis particular. La persona aprende algunos aspectos o variaciones de su cultura, podemos decir que aprende un cierto número de microculturas diferentes, o parcialmente diferentes, y lo hace en el transcurso de un tiempo y con unas concretas interacciones, de modo que el bagaje cultural de una persona concreta depende de la forma en que llevó a cabo esa interacción con su entorno ${ }^{19}$ a lo largo del discurrir de su vida.

No sólo las personas muestran ese dinamismo y flexibilidad sino que también las culturas, a no ser que queramos darles una sustantividad, una vida al margen de sus miembros, se hayan continuamente en proceso de recreación, según son interpretadas y renegociadas por sus miembros. No existe cultura alguna que no mantenga instituciones especializadas, o momentos específicos, en los que se intensifican los movimientos y actividades que la hacen similar a un foro en el que se negocia y renegocia el significado de algunos de sus elementos culturales, se buscan nuevas explicaciones de las acciones y se exploran mundos posibles.

La comprensión entre personas de diferentes culturas es posible porque ni las culturas son tan homogéneas y fijadas que no evolucionen, ni los miembros que pertenecen a ellas no pueden repensarlas, recrearlas en función de dar nuevas respuestas que sean satisfactorias a los imprevistos problemas que la vida va presentando. Y nuestra vida euro-

17. Gala, A. (1994), «Tres razas, dos ejemplos». Semana El País. 30 de octubre, p. 122.

18. Bruner, J. S. (1988), Realidad mental y mundos posibles. Barcelona, Gedisa, p. 152.

19. Caro Baroja, J. (1986), «Género biográfico y conocimiento antropológico». Discurso de Ingreso en la Real Academia Española. 
pea, española, la de cada día, nuestra vida ordinaria tenemos que resolverla conjuntamente, relacionándonos las personas de una cultura con las personas de otra cultura porque con-vivimos, vivimos unos con otros. El problema o la cuestión central no es si es posible comprendernos sino cómo alcanzar esa comprensión. Y en el cómo hacerlo algo tiene que decir la educación, aunque obviamente no es sólo una mera cuestión educativa sino también una praxis política desde una exigencia moral.

Digo que la comprensión entre culturas es una exigencia moral porque implica, como base y supuesto fundamental, el reconocimiento de los «otros» como personas; y es una praxis política porque es necesario que los Derechos Humanos, recogidos en las mayorías de las Constituciones, sean plasmados en planteamientos políticos ordinarios basados en la justicia. Si esto no es así, los miembros de las culturas minoritarias, existentes en una sociedad, y los miembros de las culturas minoritarias de nuestro planeta tenderán a volverse resentidos y a constituir ghetos impermeables.

El reconocimiento de las otras culturas y de sus miembros no es real si no son reconocidas en aquello que las constituye, es decir, en su lengua, convicciones, valores, actitudes, usos, costumbres, comportamientos... en su integridad cultural. Ese reconocimiento implica, como veremos a continuación, la tolerancia.

\section{LA TOLERANCIA ENTRE CULTURAS, UNA PREDISPOSICIÓN PARA LA COMPRENSIÓN}

Si bien el concepto de tolerancia adquiere una precisa significación a partir de los siglos XVI y XVII, producto de la reflexión sobre los graves conflictos religiosos en Europa, podemos decir, sin temor a equivocarnos, que sus antecedentes se remontan a la vieja Grecia. El método socrático de buscar, a través del diálogo con los demás, el saber y la virtud ha sido considerado como un paradigma de la actitud tolerante. Como ha puesto de manifiesto Ramón Mínguez ${ }^{20}$, la tolerancia ha sido una propuesta histórica que, circunscrita inicialmente al aspecto religioso, se ha ido ampliando a los aspectos ideológicos, políticos y morales.

En su origen etimológico, tolerancia significa paciencia, sufrimiento, capacidad de soportar. El diccionario de la Real Academia Española, en su segunda acepción, nos la define así: «Respeto y consideración hacia las opiniones o prácticas de los demás, aunque repugnen a las nuestras» ${ }^{21}$. Dos características me parecen básicas en el concepto de

20. Ramón Mínguez (1988) hace un detallado análisis de la historia y del concepto de tolerancia en su obra: La tolerancia en alumnos de la Escuela Universitaria del profesorado de E.G.B. Un análisis empírico. Valencia, Universidad de Valencia, pp. 17-99. Para el lector interesado en los jalones históricos, cfr.: Locke, J. (1985), Carta sobre la tolerancia. Madrid, Tecnos. Voltaire (1984), Tratado de la tolerancia. Barcelona, Grijalbo; Romilli, M. (1765), «Tolerance». En Diderot, D., Enciclopedie, ou dictionaire raisoné des sciences, des arts et des metiers. Tomo VI. Naufchantel, Samuel Faulche et compagnie; Mill, J. S. (1979), Sobre la libertad. Madrid, Alianza Editorial.

21. Real Academia Española (1984), Diccionario de la lengua Española. Tomo II, p. 1317. Para un análisis de las características de la tolerancia y sus diversos significados, a partir del diccionario de la Real Academia Española y del Oxford English Dictionary. Cfr. Ibáñez-Martín, J. A. (1984), «Tolerancia y educación», en Educación y sociedad plural. Actas del VIII Congreso Nacional de Pedagogía. Tomo II. Santiago de Compostela, Universidad, pp. 95-103. 
tolerancia; la primera es la disposición del sujeto a soportar y sufrir a aquellas personas que sostienen creencias y prácticas diferentes a las suyas, y con las cuales el encuentro personal es perturbador de las creencias y prácticas que le son propias; y esa perturbación puede alcanzar el límite de la repugnancia.

La segunda característica radica en que esa disposición para soportar surge desde el respeto y la consideración que es debida al «otro». El sujeto tolerante está afectado negativamente por aquello que tolera, las opiniones y prácticas que no comparte, pero tiene sus razones para «respetarlas» y «considerarlas»; y esas razones son la dignidad personal del otro en la que reconoce su racionalidad, su capacidad de haber descubierto aspectos de verdad, que no son los que él ha alcanzado; y su libertad, su capacidad de autodeterminarse, de realizar acciones reguladas por normas que tampoco son las que en él rigen la conducta.

Frente a lo que comúnmente se cree, la persona tolerante no es aquella a quien todo le parece bien porque mantenga una posición relativista respecto a la verdad o respecto a las costumbres; la persona tolerante, por el contrario, es aquella que está comprometida con sus convicciones y con unas normas de acción, es aquella que cree en la verdad y en la justicia de sus propias posiciones y por ello, precisamente porque cree en su verdad y en su justicia, padece la convicciones y acciones de los otros. El relativista, para quien no existe la verdad y para quien los ideales normativos de la acción no son universalizables, no tiene porqué padecer o sufrir las convicciones o costumbres de los demás; puesto que todas las convicciones y costumbres le parecen que son más o menos igualmente defendibles, desde el punto de vista intelectual, no es necesario que sea tolerante.

Si bien una persona tolerante está comprometida con unas convicciones y normas de acción, también está convencida de que el errar es humano y, además, algo que nos sucede a cada paso. Lo que tanto Sócrates como Locke y Voltaire subrayaron fue el hecho de la ignorancia humana, que tiene como consecuencia ética ineludible la tolerancia. Si yo puedo estar equivocado, tu puedes tener razón o quizás es fácil que ambos estemos equivocados; este principio de falsabilidad, formulado por K. Popper ${ }^{22}$, no sólo es epistemológico sino también ético. Si yo espero aprender de ti, y si tú deseas aprender en interés de la verdad, yo tengo no sólo que tolerarte sino que reconocerte como alguien potencialmente igual; la unidad e igualdad potencial de todos constituye, en cierto modo, un requisito previo de nuestra disposición a discutir racionalmente las cosas.

La tolerancia tiene, por lo tanto, dos dimensiones; por una parte la negativa del padecer y sufrir; por otra, la positiva de la búsqueda de la verdad y de la justicia desde el pluralismo y la diversidad. Si bien la tolerancia, como dijimos, excluye el relativismo exige, por otro lado, el pluralismo. Por ello los auténticos enemigos de la tolerancia son el dogmatismo y el autoritarismo. En ellos es precisamente donde la tolerancia encuentra su límite; el autoritarismo y el dogmatismo quizás sean lo básico que la tolerancia no pueda tolerar.

El reconocimiento de la dignidad de la persona con competencia racional para buscar la verdad y comunicar sus hallazgos y con competencia para buscar la felicidad, exige la tolerancia, como actitud radical de respeto, de intentar comprender las razones de los otros y de buscar cooperativamente, mancomunadamente con ellos, la verdad y la justicia.

22. Popper, K. (1994), «Tolerancia y responsabilidad del intelectual», en Búsqueda de un mundo mejor. Barcelona, Paidós, pp. 241-258. 


\section{EL PROCESO DE EDUCACIÓN EN LA TOLERANCIA}

La actitud de la tolerancia o sus contrarios, el autoritarismo y el dogmatismo, son enseñados-aprendidos en los contextos sociales en los que se vive. $Y$ esos contextos desgraciadamente no son favorables, como nos lo manifiestan los hechos cotidianos de xenofobia y racismo que están sucediendo. Si la realidad social es así y la insensatez continúa estando presente, el sistema educativo tiene que tomar partido sobre estos asuntos, como certeramente ha señalado el Ministerio de Educación y Ciencia ${ }^{23}$ al considerar la educación en la tolerancia como un objetivo fundamental de la L.O.G.S.E.

La tolerancia, como dijimos anteriormente, es una exigencia ética y además tiene que hacerse posible desde el compromiso con una determinada práctica política: el respeto efectivo a los derechos humanos y la defensa de la justicia en una sociedad plural. Pero la tolerancia también necesita ser enseñada y aprendida, por lo que el sistema de educación tiene que estar comprometido con ella. La conciencia de esa necesidad de compromiso está surgiendo en los últimos años, como manifiestan los abundantes escritos y debates que, en obras colectivas, congresos, symposios y jornadas, tienen por objeto la educación intercultural ${ }^{24}$.

Una educación intercultural que dé respuestas a los interrogantes de nuestro tiempo debe tener, a juicio de Ortega y Mínguez ${ }^{25}$, las siguientes características: promoción y defensa de los valores democráticos; valoración y promoción del pluralismo lingüístico; cultivo metodológico del diálogo; aceptación de las diferencias como factor de maduración; establecimiento de normas y propuestas de valores que reflejen y legitimen la diversidad cultural y étnica; desarrollo de la empatía, entendimiento y comprensión de la diversidad, de la semejanza e interdependencia para favorecer la convivencia en una sociedad culturalmente diversa; interiorización de principios morales que regulen la conducta en una sociedad culturalmente diversa. En definitiva, la educación intercultural, según mi opinión, tiene que tener, como objetivo fundamental, la promoción de la actitud de la tolerancia, de la que son manifestaciones las características señaladas.

Para la consecución de la actitud de la tolerancia, como objetivo de la educación, tienen que generarse los procesos educativos que sean los más adecuados. Y esos procesos educativos, a mi parecer, tienen que orientarse, en los centros y en las aulas, en tres direcciones referidas una a los procedimientos, otra a los contenidos y la tercera a las técnicas.

En cuanto a los procedimientos, para educar en la tolerancia, el más básico y efectivo es la promoción del diálogo entre los alumnos y de los alumnos con los profesores. Cuando un alumno es entrenado en la habilidad de escuchar al otro desde sus razones,

23. Popper, K. (1994), Centros educativos y calidad de la enseñanza. Propuesta de actuación. Madrid, M. E. C., p. 45.

24. Como muestra de ello pueden examinarse: Cfr. (1992), Educación Intercultural en la Perspectiva de la Europa Unida. Actas del X Congreso Nacional de Pedagogía. 2 Tomos, Salamanca, S.E.P.; (1993), Educación y Democracia. Actas de las Jornadas Internacionales sobre Educación y Democracia. Murcia, Caja Murcia; Santos Rego, M. (ed.) (1994), Teoría y práctica de la educación intercultural. Obr. cit.

25. Ortega, P.; Mínguez, R., «Educación intercultural y democracia». En Sáez, J.; Ortega, P. (eds.), Educación y democracia. Obr. cit., pp. 141-142. 
valores e intereses, se está iniciando en el camino de la comprensión y aprecio de otros puntos de vista, de otras formas de vida y de otras actuaciones que no son las suyas. $\mathrm{Si}$ es una escucha activa, si es un auténtico diálogo, irá reelaborando su propio pensamiento y valoraciones desde las informaciones recibidas del otro. Un diálogo implica no sólo escuchar sino también estar dispuesto a dar razones, a justificar las propias posiciones ${ }^{26}$. Unos alumnos, o cualesquiera personas que realmente dialoguen, escuchen y den razones, han introducido un crítico dentro de su conciencia, puesto que están dispuestos a examinar sus argumentos y los del otro, y están dispuestos a discutir los problemas, a mirar las situaciones desde los puntos de vista de los otros además del propio punto de vista.

El diálogo, como procedimiento para la solución de conflictos, ha alcanzado, en la filosofía moral y política, categoría de corriente de pensamiento ${ }^{27}$. Sin embargo, en las prácticas ordinarias de la sociedad y en las relaciones de aula, no se le presta la debida atención, a pesar de las recomendaciones de los Organismos Internacionales. En su vigésimo primera sesión, la Conferencia General de la Unesco reafirmó que la cultura de un pueblo constituye el fundamento de los valores en los que todo ser humano y toda comunidad reconoce su identidad. Destacó que la toma de conciencia de la identidad cultural constituye un factor esencial del desarrollo y, al mismo tiempo, la base de relaciones, diálogos e intercambios entre culturas aptos para contribuir a la comprensión internacional y a la $\operatorname{paz}^{28}$. Según la citada conferencia, el diálogo, a partir de la propia identidad cultural, es el procedimiento básico para la tolerancia hacia otras culturas y para la paz.

Un segundo procedimiento, muy conectado con el anterior, es garantizar el pluralismo crítico en las ideas, ciencias, religiones y costumbres. El pluralismo crítico es aquella posición que admite la discusión racional sobre cualquier creencia, valoración o conducta; y ello desde la lealtad a cada una de las propias tradiciones culturales. Probablemente haya diferencias radicales en lo que se entiende por racionalidad, según sean las culturas, pero es necesario, para la promoción del diálogo entre miembros de culturas diversas, partir del supuesto de que a los demás les asisten buenas razones para sostener las creencias y las conductas que sostienen; razones que se está dispuesto a escuchar y, por supuesto, a dar.

El pluralismo crítico, como procedimiento para la tolerancia, es posible a partir de aquellos climas de aula en los que se promueve que los alumnos interpreten el mundo, la realidad, de forma distinta según las circunstancias de cultura, raza, clase y orientación política. Ello significa proporcionar a los alumnos las oportunidades necesarias para ser discordantes, críticos y, a veces, combativos. Así irán comprendiendo cómo las dife-

26. Cfr. Escámez, J. (1992), «Comunicación personal en contextos interculturales». Rvta. $P A D^{\prime} E$; Escámez, J. (1994), «Orientaciones para la educación en valores morales en el nivel de educación secundaria». Actas del Foro Internacional sobre educación y valores. México, I.F.I.E. Unesco; Puig, J. M. (1993), Toma de conciencia de las habilidades para el diálogo. Madrid, Aprendizaje.

27. Cfr. Rawls, J. (1978), Teoría de la justicia. México, F.C.E.; Cortina, A. (1985), Razón comunicativa y responsabilidad solidaria. Salamanca, Sígueme; Habermas, J. (1985), Conciencia moral y acción comunicativa. Barcelona, Península; Apel, K. O. (1991), Teoría de la verdad y ética del discurso. Barcelona, Paidós.

28. Varios (1990), Sobre el futuro de la educación. Hacia el año 2000. Madrid, Narcea, pp. 248-249. 
rencias culturales, raciales e ideológicas incrementan la posibilidad de diálogo, confianza y solidaridad ${ }^{29}$. Esta perspectiva permite analizar y respetar las diferencias en contextos pedagógicos que fomentan la tolerancia y no el dogmatismo.

En cuanto a los contenidos, para educar en la tolerancia, creo que habría que empezar por la enseñanza de aquellas reglas fundamentales que rigen en las sociedades plurales y que todo miembro, sea cual sea su cultura, debe respetar. En nuestra Constitución se dan aquellas reglas fundamentales de comportamiento que $\mathrm{H}$. J. Ape $\mathrm{l}^{30}$ había señalado para los ciudadanos alemanes; a) todos los miembros de la sociedad deben respetar y proteger la dignidad del hombre; b) todos deben asegurar la libertad de opinión, de religión, de convicción política, de prensa; c) todos deben respetar la igualdad de todos los individuos ante la ley, la elección profesional, la educación ${ }^{31}$. Estos contenidos constitucionales tendrían que ser objeto de enseñanza-aprendizaje para que los alumnos se comportaran como exigen nuestras leyes. Así el respeto y garantía de la dignidad personal, la libertad y la igualdad serían reconocidas como reglas fundamentales para ser vividas en la vida cotidiana de la escuela y ser utilizadas como normas de conducta. $\mathrm{Y}$ con ello, la tolerancia, la regulación racional de conflictos y la apertura hacia los otros serían discutidas en las situaciones reales de la vida escolar.

Un segundo núcleo de contenidos, como ya expuse siguiendo a Victoria Camps, podría ser la enseñanza de los derechos humanos; en ellos se reflejan valores de alcance universal que son compartidos, o deberían ser compartidos, por todas las culturas. Como respetarlos y reconocerlos en abstracto significa muy poco, aunque nunca la declaración de principios es inútil, es necesaria una educación que los tenga como objetos de enseñanza-aprendizaje. Conocer y apreciar el contenido de la Declaración de los Derechos Humanos es un factor que facilita la aparición de conductas tolerantes. Es importante, como ha dicho Puig ${ }^{32}$, transmitir el valor de la legislación, propia e internacional, en tanto que esfuerzo colectivo para optimizar la vida de acuerdo a criterios de justicia.

Referido a las técnicas, he de decir que pueden llevarse al funcionamiento del aula algunas de ellas que tienen suficientemente probada su eficacia para educar la actitud de tolerancia. Un equipo de profesores de las universidades de Valencia y Murcia aplicamos técnicas de cooperación (especialmente la técnica «puzzle» de Aronson y la técnica de «equipos de juego-concurso» de De Vries) a alumnos de Bachillerato, con resultados muy positivos ${ }^{33}$. Lo que nos propusimos fue hacer posible las condiciones para que los alumnos, participando y cooperando en las actividades del aula, se comprendieran y se estimaran en sus diferencias. Una revisión actualizada, sobre los resultados del aprendizaje cooperativo para la resolución de conflictos en contextos de educación intercultural,

29. Giroux, H. A.; Flecha, R. (1992), Igualdad educativa y diferencia cultural. Espluges de Llobregat, El Roure, p. 21.

30. Apel, H. J. (1992), «La educación en valores en una sociedad plural». En Sáez, J.; Ortega, P. (eds.), Educación y democracia. Obr. cit., p. 33.

31. Constitución Española, art. 10.1; art. 14; art. 16.1; art. 20.1; art. 27.1.

32. Puig, J. M. (1992), «Minorías étnicas y educación democrática: Hacia el interculturalismo». En Sáez, J.; Ortega, P., Educación y democracia. Obr. cit., pp. 130.131.

33. Escámez, J.; Ortega, P. y Gil, R. (1989), «Programa pedagógico para educar en la tolerancia a alumnos de B.U.P.». Revista Española de Pedagogía, n $^{\circ} 182$, pp. 25-48. 
nos la ofrece Santos Rego ${ }^{34}$, que afirma: «El auténtico valor y la mejor aportación posible del aprendizaje cooperativo en la escuela y en la comunidad es de ayudar al logro de un multi/interculturalismo para la mejor coexistencia/convivencia étnica y cultural en un marco de rica diversidad humana».

Quisiera hacer algún apunte sobre unas técnicas, a mi juicio de primer orden, para educar en la tolerancia como son las técnicas del Role Taking ${ }^{35}$. En efecto, si conceptualizamos la tolerancia como una actitud entonces es una predisposición evaluativo-afectiva hacia los otros. Ello significa que no es suficiente comprender las perspectivas de los otros, como postura intelectual, sino que es necesario dar un paso más: comprometerse con ellos, prestándoles ayuda y un cuidado responsable. Las técnicas de Role Taking creo que son un buen instrumento para ensalzar la sensibilidad hacia los argumentos, sentimientos y necesidades de los otros, porque permiten imaginar sus experiencias vitales desde donde surgen tales argumentos, sentimientos y necesidades.

La paz es una utopía que merece nuestros sueños e ilusiones; la tolerancia hacia otras personas y otras culturas es el reconocimiento de la dignidad y de la libertad de los humanos; educar para la tolerancia es trabajar para la justicia, y un mundo justo es un mundo en paz; y existen los procedimientos y técnicas pedagógicas que nos permiten hacerlo. Considero que la opción por este tipo de educación es fundamentalmente una opción moral.

34. Santos Rego, M. (1994), «La dimensión interactiva y el aprendizaje cooperativo como vía de educación intercultural». En Santos Rego, M. (ed.), Teoría y práctica de la educación intercultural. Obr. cit., p. 138.

35. Para una información actualizada cfr. Rodríguez, J. M. (1994), Análisis histórico del RoleTaking tomando como referencia los presupuestos de Kohlberg; El Role-Taking como un prerrequisito para el desarrollo moral. Tesis doctoral. Universidad de la Laguna. Tenerife. 